УДК 37.088

DOI $10.31483 / \mathrm{r}-21456$

\title{
А.А. Михайленко
}

\section{КРИТЕРИИ ОЦЕНКИ КОРПОРАТИВНОЙ КУЛЬТУРЫ ОБЩЕОБРАЗОВАТЕЛЬНОЙ ОРГАНИЗАЦИИ}

Аннотация: в работе предложены критерии для оценки корпоративной культуры в школе как организаџии особого типа. Рассмотрены основные подходы к оцуенке корпоративной культуры организацฺй, на основе которых выработана система критериев для ее оценки в образовательных организачиях. B рамках статьи предложена относительно независимая система критериев и показателей для оценки корпоративной культуры применительно к специфике образовательной организаџии. Предложенная система предполагает оценивать корпоративную культуру в баллах. Это позволяет вести мониторинг и сравнивать уровень данной культуры в разных школах и в динамике.

Ключевые слова: корпоративная культура, образовательная организация, анализ корпоративной культуры, критерии оченки, независимая оценка, показатели оценки.

\section{A.A. Mikhailenko}

\section{CRITERIA FOR EVALUATION OF CORPORATE CULTURE OF THE GENERAL EDUCATION ORGANIZATION}

Abstract: in article criteria for assessment of corporate culture at school as the organizations of special type are offered. The main approaches to assessment of corporate culture of the organizations on the basis of which the system of criteria for it assessment in the educational organizations is developed are considered. Within article rather independent system of criteria and indicators for assessment of corporate culture, in relation to specifics of the educational organization is offered. Offered systems assumes assessment of corporate culture in points. It allows to conduct monitoring and to compare the level of this culture at different schools and in dynamics. 
Keywords: corporate culture, educational organization, analysis of corporate culture, evaluation criteria, independent assessment, assessment indicators.

Продуманная корпоративная культура на современном этапе рассматривается, как одно из условий эффективной работы любой организации. В этой связи сегодня существует и разрабатывается множество различных шкал для оценки уровня корпоративной культуры (в ходе количественного анализа) и методик оценки ее модальности и типа (в ходе качественного анализа) [5, с. 34].

Многие из методов оценки корпоративной культуры считаются достаточно универсальными, но в то же время, они подходят далеко не для всех типов организаций. И наиболее выраженную специфику в данном контексте имеют общеобразовательные организации, поскольку их деятельность достаточно строго регламентирована, работа сотрудников отличается присутствием творческого компонента, а качество оказываемых услуг трудно измеримо.

Существует ряд наиболее часто используемых комплексных методик измерения корпоративной культуры - таблица 1.

Таблица 1

Методики оценки корпоративной культуры

\begin{tabular}{|l|l|}
\hline \multicolumn{1}{|c|}{ Комплексные методики } & \multicolumn{1}{|c|}{ Объект исследования, измеряемые показатели в рамках } \\
применения методики
\end{tabular}

По представленной таблице статистических методик оценки корпоративной культуры, можно отметить, что часть методик имеют сходные черты и достаточно сложны в исследовании обработки результатов [3, с. 67]. Часть методик- 
простые методики-анкеты (в процессе анализа раздают сотрудникам, которые субъективно оценивают в баллах различные параметры), которые достаточно субъективны - сотрудники, заполняя их, выражают собственное мнение по каждому из параметров, которое может быть искажено их личным восприятием. Кроме того, представленные методики, в большей степени, подходят для коммерческих организаций, а не для бюджетных, к каковым относятся общеобразовательные организации.

Это обуславливает актуальность предложения такой системы критериев оценки корпоративной культуры, которая будет применима именно для общеобразовательной организации и при этом, будет лишена субъективизма.

В частности, для оценки корпоративной культуры как системы моделей поведения членов общеобразовательной организации, которая возникает при приспособлении их к взаимодействию между собой и с внешней средой, можно предложить систему следующих критериев и показателей (таблица 2).

Таблица 2

Система критериев и показателей для оценки корпоративной культуры общеобразовательной организации

\begin{tabular}{|c|c|c|}
\hline Критерий & Показатели & $\begin{array}{c}\text { Значения показателя } \\
\text { и оценка в баллах }\end{array}$ \\
\hline \multirow[t]{2}{*}{$\begin{array}{l}\text { Кадровый потен- } \\
\text { циал }\end{array}$} & $\begin{array}{l}\text { Доля педагогов за последний год, повыша- } \\
\text { ющих квалификацию (учитываются раз- } \\
\text { ные виды обучения, в различных аспек- } \\
\text { тах) }\end{array}$ & $\begin{array}{l}30 \% \text { и более - } 3 \text { балла; } \\
10-30 \%-2 \text { балла; } \\
\text { менее } 10 \% \text { - } 1 \text { балл. }\end{array}$ \\
\hline & $\begin{array}{l}\text { Доля руководящего состава (директор, за- } \\
\text { местители), имеющих подготовку в обла- } \\
\text { сти управления организацией (курсы, вто- } \\
\text { рое образование) }\end{array}$ & $\begin{array}{l}100 \% \text { - } 3 \text { балла; } \\
50 \% \text { - } 2 \text { балла; } \\
\text { менее } 50 \% \text { - } 1 \text { балл. }\end{array}$ \\
\hline \multirow[t]{2}{*}{ Стиль руководства } & $\begin{array}{l}\text { Доля управленческих решений (развитие } \\
\text { организации, особенности работы, страте- } \\
\text { гические цели, принятие нормативных до- } \\
\text { кументов и др.), принимаемых на педаго- } \\
\text { гическом совете }\end{array}$ & $\begin{array}{l}50 \% \text { - } 3 \text { балла; } \\
30 \% \text { - } 2 \text { балла; } \\
\text { менее } 10 \% \text { - } 1 \text { балл. }\end{array}$ \\
\hline & $\begin{array}{l}\text { Доля управленческих решений, принимае- } \\
\text { мых без ведома педагогического коллек- } \\
\text { тива. }\end{array}$ & $\begin{array}{l}\text { менее } 10 \% \text { - } 3 \text { балла; } \\
50 \% \text { - } 2 \text { балла; } \\
\text { более } 50 \% \text { - } 1 \text { балл. }\end{array}$ \\
\hline $\begin{array}{l}\text { Атмосфера в кол- } \\
\text { лективе }\end{array}$ & $\begin{array}{l}\text { Доля сотрудников, имеющих между собой } \\
\text { неформальные отношения (дружбу, }\end{array}$ & $\begin{array}{l}\text { более } 50 \% \text { - } 3 \text { балла; } \\
10-50 \% \text { - } 2 \text { балла; } \\
\text { менее } 10 \% \text { - } 1 \text { балл. }\end{array}$ \\
\hline
\end{tabular}




\begin{tabular}{|c|c|c|}
\hline & $\begin{array}{l}\text { взаимодействие по рабочим вопросам) вне } \\
\text { рабочего времени }\end{array}$ & \\
\hline & $\begin{array}{l}\text { Число традиций, существующих более } 5 \\
\text { лет }\end{array}$ & $\begin{array}{l}\text { более } 5 \text { - } 3 \text { балла; } \\
2-4-2 \text { балла; } \\
\text { менее } 2-1 \text { балл. }\end{array}$ \\
\hline \multirow[t]{2}{*}{$\begin{array}{l}\text { Гибкость управле- } \\
\text { ния }\end{array}$} & $\begin{array}{l}\text { Число нововведений в области повышения } \\
\text { эффективности работы организации, пред- } \\
\text { ложенных рядовыми сотрудниками и } \\
\text { внедренных в деятельность. }\end{array}$ & $\begin{array}{l}\text { более } 5 \text { - } 3 \text { балла; } \\
2-4-2 \text { балла; } \\
\text { менее } 2 \text { - } 1 \text { балл. }\end{array}$ \\
\hline & $\begin{array}{l}\text { Доля внешних тенденций в системе обра- } \\
\text { зования, внедряемых в практику работы } \\
\text { организации }\end{array}$ & $\begin{array}{l}\text { более } 50 \% \text { - } 3 \text { балла; } \\
10-50 \% \text { - } 2 \text { балла; } \\
\text { менее } 10 \% \text { - } 1 \text { балл. }\end{array}$ \\
\hline \multirow[t]{2}{*}{$\begin{array}{l}\text { Открытость обще- } \\
\text { образовательной } \\
\text { организации }\end{array}$} & $\begin{array}{l}\text { Число образовательных организаций-парт- } \\
\text { неров на долгосрочной основе (вузы, кол- } \\
\text { леджи, другие школы, дома творчества) }\end{array}$ & $\begin{array}{l}\text { более } 5 \text { - } 3 \text { балла; } \\
2-4-2 \text { балла; } \\
\text { менее } 2 \text { - } 1 \text { балл. }\end{array}$ \\
\hline & $\begin{array}{l}\text { Число общественных и коммерческих ор- } \\
\text { ганизаций-партнеров на долгосрочной ос- } \\
\text { нове (фонды, общественные организации, } \\
\text { коммерческие предприятия) }\end{array}$ & $\begin{array}{l}\text { более } 5 \text { - } 3 \text { балла; } \\
2-4 \text { - } 2 \text { балла; } \\
\text { менее } 2 \text { - } 1 \text { балл. }\end{array}$ \\
\hline
\end{tabular}

По таблице 2 можно отметить, что в рамках оценки корпоративной культуры общеобразовательной организации предложена система из пяти критериев, для каждого из которых установлено по два показателя и соответствующие оценки в баллах.

Предложенная система оценки, как представляется, позволяет сделать акцент на тех факторах корпоративной культуры, которые значимы именно для общеобразовательной организации, опуская менее репрезентативные для школы критерии оценки (также возможно адаптировать представленную систему для оценки корпоративной культуры вуза, колледжа или дошкольной организации). Процесс оценки, поскольку предполагает установление численных (процентных) параметров, в меньшей степени субъективен, нежели, например, опрос мнения сотрудников относительно параметров корпоративной культуры.

Показатели в ходе оценивания могут быть выражены в баллах, что позволяет дать количественную оценку уровню корпоративной культуры, проводить сравнение корпоративной культуры, например, при сопоставлении разных общеобразовательных организаций. Также балльная система оценки позволяет вести мониторинг уровня корпоративной культуры в отдельно взятой школе (например, проводя ежегодное исследование).

4 https://phsreda.com

Содержимое доступно по лицензии Creative Commons Attribution 4.0 license (CC-BY 4.0) 
Также подобная система критериев позволяет руководителю общеобразовательной организации обращать внимание на те факторы, которые наиболее позитивно отражаются на процессе формирования корпоративной культуры школы, и следовательно, развивать соответствующие условия повышения корпоративной культуры.

Таким образом, представленная система критериев и показателей для оценки (количественного анализа) корпоративной культуры общеобразовательной организации позволяет давать сравнительно объективную оценку, проста в использовании, обработке и представлении результатов оценки, ориентирована на те параметры и условия корпоративной культуры, которые наиболее значимы для успешного функционирования школы, как организации особого типа.

\section{Сиисок литературы}

1. Бахмутский А.Е. Педагогика: Учебник / А.Е. Бахмутский [и др.]. - СПб.: Питер пресс, 2017. - 304 с.

2. Левитан К.М. Юридическая педагогика: Учебник для вузов по направлению «Юриспруденция» / К.М. Левитан. - М.: Норма; Инфра-М, 2017. - 415 с.

3. Седельников А.А. Управляющий совет как катализатор создания гражданского общества. Первые итоги деятельности общественного органа управления / А.А. Седельников // Народное образование. - 2016. - №4. - С. 110-113.

4. Шекшня С.В. Управление персоналом современной организации: Учебно-практическое пособие. - Изд. 5-е, перераб. и доп. - М.: ЗАО «Бизнесшкола «Интел-Синтез», 2002. - 368 с.

5. Шекова Е.Л. Трансформация организационных структур управления: опыт музеев / Е.Л. Шекова // Некоммерческие организации в России. - 2014. №2. - C. 23-31.

\section{References}

1. Bakhmutskii, A. E. (2017). Pedagogika., 304. SPb.: Piter press.

2. Levitan, K. M. (2017). Iuridicheskaia pedagogika., 415. M.: Norma; M.: Infra-M. 
3. Sedel'nikov, A. A. (2016). Upravliaiushchii sovet kak katalizator sozdaniia grazhdanskogo obshchestva. Pervye itogi deiatel'nosti obshchestvennogo organa upravleniia. Narodnoe obrazovanie, 4, 110-113.

4. Shekshnia, S. V. (2002). Upravlenie personalom sovremennoi organizatsii., 368. M.: ZAO "Biznes-shkola "Intel-Sintez".

5. Shekova, E. L. (2014). Transformatsiia organizatsionnykh struktur upravleniia: opyt muzeev. Nekommercheskie organizatsii v Rossii, 2, 23-31.

Михайленко Анастасия Александровна - магистрант кафедры «педагогики и психологии профессионального образования» ФГАОУ ВО «Северо-Кавказский федеральный университет», Россия, Ставрополь.

Mikhailenko Anastasia Aleksandrovna - North-Caucasian Federal University, Department of «Pedagogy and Psychology of Vocational Education», Russia, Stavropol, undergraduate. 